\title{
Práticas Organizacionais e Estrutura de Relações no Campo do Desenvolvimento Metropolitano
}

\author{
Organizational Practices and Relationship Structure in the Field of Metropolitan \\ Development
}




\title{
RESUMO
}

O objetivo deste estudo consistiu em verificar as relações existentes entre as organizações responsáveis pelo planejamento urbanístico dos municípios da Região Metropolitana de Curitiba [RMC], Brasil, e como essas relações influenciam as práticas de desenvolvimento urbano. No artigo estabelecemos uma definição de práticas organizacionais em consonância com as práticas sociais e, empiricamente, indagamos sobre os reflexos do modelo de urbanismo da capital paranaense nos municípios daquela região. O quadro teórico de referência é caracterizado pela teoria institucional em sua vertente estruturacionista. Na estratégia de condução da pesquisa, descrevemos as relações entre as organizações dos municípios da RMC por meio da análise de redes sociais. Já as práticas de desenvolvimento urbano foram identificadas com base em dados secundários e depoimentos de 62 gestores públicos. Os resultados demonstram uma baixa densidade nas relações diretas entre as prefeituras, com a rede tornando-se mais densa na presença de órgãos do Governo Estadual. Apesar da pequena influência direta do urbanismo de Curitiba nos outros municípios da região metropolitana, características de dominação, significação e legitimação revelam algumas práticas isomórficas, bem como a presença de fatores culturais brasileiros influenciando a maneira de atuar das organizações públicas.

Palavras-chave: instituições; práticas sociais; análise de redes sociais; dualidade da estrutura.

\begin{abstract}
The aim of this study is to examine the relationships between the organizations responsible for urban planning in the towns of the Metropolitan Region of Curitiba, Brazil, and how these relationships influence urban development practices. In the article we establish a definition of organizational practices in accordance with social practices and, empirically, we enquire how the urbanism model of the capital city of Paraná State impacts on the towns in the region. The theoretical frame of reference is characterized by the institutional theory in its structurationist approach. When describing the research strategy, we outline the relationships between the organizations of the towns of the Metropolitan Region of Curitiba through a social network analysis. Meanwhile, the urban development practices were identified based on secondary data and statements by 62 public managers. The results show a low density in direct relationships between town halls, with the network becoming more dense when State Government departments are involved. Despite the low level of direct influence of Curitiba's urbanism on the other towns of the metropolitan region, characteristics of domination, signification and legitimization reveal some isomorphic practices and the presence of Brazilian cultural factors influencing the way public organizations act.
\end{abstract}

Key words: institutions; social practices; social network analysis; duality of structure. 


\section{INTRODUÇÃO}

A urbanização brasileira tem nas metrópoles os principais focos de sua concretização. Nove regiões metropolitanas foram reconhecidas formalmente na década de 70 do século passado: Belém, Belo Horizonte, Curitiba, Fortaleza, Porto Alegre, Recife, Rio de Janeiro, Salvador e São Paulo. Após a Constituição de 1988, outras metrópoles foram formalizadas.

Esses conglomerados urbanos requerem os chamados serviços de interesse comum, isto é, serviços que são úteis para mais de um município. As ações no sentido de solucionar evidentes problemas urbanos de todos os níveis exigem a integração dos municípios componentes de um espaço territorial, ocasionando a provável formação de uma rede de relacionamentos.

Nesse contexto está presente a Região Metropolitana de Curitiba [RMC], com números considerados preocupantes em um retrospecto comparativo da evolução demográfica. De acordo com dados do Governo do Paraná, em 1970 havia 869.837 habitantes, aproximadamente 13\% da população total do Estado do Paraná. Em 2005, decorridos 35 anos, portanto, este número saltou para 3,2 milhões de pessoas, contabilizando aproximadamente $31 \%$ do total de habitantes do Paraná.

São números que se fazem acompanhar de elevada desigualdade social e de altos índices de desemprego, entre outros problemas, atestando claramente a fragilidade que existe no entorno das grandes metrópoles brasileiras. São situações que exigem soluções nos campos político, social e econômico. Ou seja, respostas da gestão pública que favoreçam uma administração urbana mais adequada.

Assim, o pressuposto da existência de uma rede de relações entre os órgãos responsáveis pelo planejamento urbanístico ${ }^{(1)}$ dos municípios da Região Metropolitana de Curitiba norteou o presente estudo. Nessa linha de análise, o objetivo deste artigo é descrever de que modo a estrutura de relacionamento influencia as práticas de desenvolvimento urbano adotadas pelos municípios integrantes da rede interorganizacional da RMC; e, desta maneira, verificar prováveis reflexos do modelo urbanístico curitibano nos municípios daquela região.

A análise da rede de relacionamentos entre os municípios da RMC é levada a efeito com o suporte da teoria institucional na sua vertente estruturacionista (Giddens, 1978, 2000, 2003). Esse tipo de análise tem-se mostrado eficaz nas pesquisas em organizações de diferentes tipos tanto no Brasil como no exterior. Aqui a investigação envolve práticas de desenvolvimento urbano em um sistema social definido, com interesses eminentemente públicos. Assim, com a finalidade de fundamentar o presente estudo, o artigo está estruturado em diversas seções que abrangem um quadro teórico de referência, procedimentos metodológicos, análise e interpretação de dados, e considerações finais.

\section{QUADRO TEÓRICO DE REFERÊNCIA}

Os estudos no campo da teoria das organizações não contemplavam as relações interorganizacionais até surgirem considerações sobre o limite das organizações em relação ao seu ambiente. Da mesma forma, somente após o entendimento pelos sociólogos que a comunidade urbana constitui uma rede de organizações, as relações inteorganizacionais emergiram como sendo relevantes e se tornaram foco de análise dos pesquisadores organizacionais (J. P. Scott, 2000). A partir daí vem crescendo significativamente o espaço dedicado aos estudos sobre redes no mundo acadêmico.

Oliver (1990), ao estudar as condições sob as quais os relacionamentos se formam, afirma que fatores ambientais e interorganizacionais aumentam a probabilidade de diferentes contingências: a) necessidade - ligações entre organizações de natureza legal ou regulatória, que normalmente não ocorreriam voluntariamente; b) reciprocidade - evidenciada pela cooperação e colaboração, uma vez 
que as relações são intencionais e visam objetivos mútuos; c) assimetria - ao contrário da reciprocidade, refere-se às relações de poder e controle, tanto das organizações quanto dos seus recursos; d) eficiência - orientada preponderantemente para a capacidade produtiva interna de cada organização; e) estabilidade - pressiona na formação de relações com o objetivo de vencer as incertezas ambientais; e f) legitimidade - justifica a existência da organização no ambiente institucional em que está inserida.

Nota-se que as relações das organizações podem se manifestar sob as mais diversas formas, desde a reciprocidade e cooperação até relações restringidas por forças coercitivas ou por relações de poder. Dessa forma, dependendo da natureza da transação, da capacidade das organizações e do contexto em que os atores se relacionam, uma dessas manifestações pode ser predominante. Assim, para a explicação das relações, reputamos de importância a identificação dessas manifestações por meio da análise das ações organizacionais dos atores integrantes da rede. Essencialmente no que se refere à competitividade, à cooperação, e às relações de poder e de conflito.

Mizruchi e Galaskiewicz (1994) destacam três diferentes abordagens que podem ser adotadas para o estudo das relações interorganizacionais: dependência de recursos, foco nas classes sociais e visão institucional. O princípio básico para a primeira é que as organizações operam em ambientes turbulentos e incertos, em que procuram obter controle sobre recursos críticos. A abordagem de classe social enfatiza formas de dominação e predominância dos interesses de determinadas classes. A teoria institucional considera a importância de sistemas culturais, partindo da idéia de que as organizações agem não apenas de acordo com cálculos racionais, mas também de acordo com as pressões presentes no ambiente em que se encontram socialmente imersas. No entanto, independentemente da escolha adotada, todas essas perspectivas podem se valer da análise de redes para enriquecimento dos seus estudos.

\section{Análise de Redes}

A análise de redes, como método de investigação de estruturas sociais, deve partir do pressuposto da rejeição das tentativas de se explicar o comportamento humano ou o processo social somente em termos dos atributos dos atores (Wasserman \& Faust, 1994). O comportamento social é tanto resultado da posse individual de atributos e normas como também o resultado de seu envolvimento na estrutura das relações sociais (Wellman, 1988); ou seja, o comportamento pode ser analisado por meio de dados de atributos e dados relacionais.

A análise de redes verifica estruturas e sistemas em que seria quase impossível descrever sem uso de conceitos relacionais, provendo tanto uma avaliação descritiva como testes de hipóteses sobre propriedades estruturais (Wasserman \& Faust, 1994). Seus fundamentos podem e precisam ser analisados de acordo com diversos critérios e medidas. A maioria dos autores da área prefere denominá-las de dimensões de uma rede organizacional.

Entre as primeiras dimensões a serem utilizadas pelos analistas sociais, destaca-se a centralidade dos atores em suas redes sociais, indicando a proeminência de alguns, quanto ao número de conexões e contatos diretos. Atores no centro da rede são estruturalmente dominantes (Galaskiewicz, 1979). Os pesquisadores Knoke e Burt (1983) conceituam dois estratos de atores associados à posição da organização na rede: proeminentes e periféricos. Atores proeminentes são altamente visíveis, em razão do seu envolvimento em relações substantivamente importantes, comparados aos que sustentam poucas relações ou estão no anonimato. Eles têm maior controle sobre recursos e informações, entre outros aspectos. A centralidade está associada ao grau em que um ator está envolvido em todas as relações no sistema, enquanto o prestígio incide em relações assimétricas, sendo também objeto de relações intensas. Nos estudos relacionais é importante atentar para a clara distinção entre centralidade e prestígio. Nesse sentido, Knoke e Burt (1983) afirmam que a centralidade pode ser mais importante quando se trata da disseminação entre os atores de processos de inovação. 
A densidade da rede é uma dimensão obtida pela proporção do número de nós, isto é, ligações observadas para o número de nós possíveis teoricamente (Granovetter, 1976; Mitchell, 1976). Em grupos pequenos, a densidade é usualmente tratada como medida de coesão do grupo. Para Cook e Whitmeyer (1992), a densidade das conexões entre organizações de uma rede exerce um dos maiores impactos sobre uma organização focal. A medida de densidade é uma das mais comuns na análise de redes, sendo problemática quando utilizada com dados de valores. Também varia de acordo com o tamanho da rede (J. P. Scott, 2000).

A Intensidade é o grau em que atores estão preparados para cumprir obrigações ou se sentirem livres para exercer os direitos implícitos na sua relação com outros atores (Mitchell, 1976). Para Uehara (1990, p. 529), "redes de altas intensidade e densidade facilitam trocas generalizadas, enquanto estruturas de baixas densidade e intensidade facilitam trocas restritas".

A frequiência dos contatos entre atores da rede é medida em dado espaço-tempo. Mitchell (1976) e Knoke e Laumann (1982) apontam que uma alta frequiência de contato pode não significar alta intensidade das relações. Essa confusão é feita, às vezes, por alguns autores.

A Multiplicidade denota a sobreposição ou redundância nas relações (Aldrich, 1979), ou seja, relações que contêm dois ou mais canais de interação. Essa dimensão pode significar aumento da estabilidade nas relações interorganizacionais. Burt (1983, p. 159) afirma que a "coordenação de relações com diferentes conteúdos é capturada pelo conceito de multiplicidade". Manifesta-se pelo número de tipos de relações que um ator estabelece com cada ator da rede (Knoke \& Burt, 1983).

Dentre as primeiras técnicas de análise de rede, destaca-se o trabalho de Moreno (1978/1934) no exame de relações dos aspectos psicológicos dos indivíduos com as configurações sociais, influenciadas por escolhas interpessoais, tais como: atração, repulsa e amizade. Foi para a compreensão dessas configurações sociais que Jacob Moreno desenvolveu a técnica do sociograma como forma de representar as propriedades formais de matrizes de relacionamentos (J. P. Scott, 2000).

Atualmente existem alguns programas para computadores que auxiliam o uso da análise de redes. Portanto, a escolha de um software a ser utilizado para auxiliar no mapeamento de uma rede é uma preferência individual. Na visão de J. P. Scott (2000), o UCINET é um dos melhores entre os disponíveis. Foi produzido por um grupo de analistas de rede na Universidade da Califórnia, Irvine [UCI]: Stephen Borgatti, Martin Everett e Linton Freeman. Teve início como um programa em Basic e hoje já está bem desenvolvido para a plataforma Windows. A versão atual é a do UCINET 6, que possui funcionalidades adequadas e boa usabilidade, atributos que são requeridos para proceder às análises necessárias.

\section{Instituições e Organizações}

A teoria institucional brotou no cenário organizacional como continuação e extensão da revolução intelectual, iniciada durante os anos 60 do século passado, que introduziu o conceito de sistemas abertos no estudo das organizações. Uma década depois, os pesquisadores começaram a reconhecer os efeitos significativos em organizações de fatores associados com forças culturais e sociais, ou seja, do ambiente institucional.

Para fins analíticos, W. R. Scott (2008) define três pilares como base da teoria institucional: a) o pilar regulativo envolve a capacidade de estabelecer regras, inspecionar a conformidade a elas e manipular sanções (recompensas ou punições) com o objetivo de nortear o comportamento social; b) o pilar normativo compreende uma dimensão prescritiva, avaliativa e obrigatória da vida social, definindo papéis e orientando sobre as maneiras mais apropriadas para neles atuar; e c) o pilar cultural-cognitivo, cujo foco é a interação dos atores sociais que, recorrentemente, (re)produzem os significados atribuídos aos objetos e às ações da vida humana associada.

No caso do pilar cultural-cognitivo, a noção de identidade é central, vez que estruturas cognitivas constituem e são constituídas por compreensões internalizadas dos atores sociais, a partir da 
interpretação da realidade em que estão imersos. Já no pilar normativo, os papéis sociais constituem o lócus de diferentes interpretações dos atores sociais, cujos atributos variam espaciotemporalmente. Assim, de acordo com W. R. Scott (2008, p. 49), os três pilares "constituem os blocos centrais das estruturas institucionais, provendo as fibras elásticas que guiam comportamentos e resistem a mudanças". Ressaltamos, contudo, que esses três pilares não devem ser visualizados de maneira estanque, mas sim de maneira articulada.

Muitos cientistas sociais têm buscado descrever e explicar diferentes tipos de estruturas organizacionais. DiMaggio e Powell (1983), pelo contrário, não perguntam o porquê de as estruturas organizacionais se diferenciarem, mas o porquê da existência de um surpreendente grau de homogeneidade nas formas e práticas organizacionais. Organizações do mesmo tipo em qualquer campo organizacional podem demonstrar considerável diversidade em suas abordagens, quando inicialmente instaladas. Todavia, na própria medida em que uma área de atividade humana vai se estabelecendo, verifica-se forte movimento em direção à homogeneidade.

Para descrever o processo de homogeneização, DiMaggio e Powel (1983) propuseram três mecanismos mediante os quais o isomorfismo institucional ocorre: coercitivo, mimético e normativo. O coercitivo é constituído por pressões formais ou informais advindas do ambiente legal e político ou da condição de dependência entre organizações. O mimético consiste na "adoção, por parte de uma organização, de procedimentos e arranjos estruturais implementados por outras organizações, a fim de reduzir a incerteza ocasionada por problemas tecnológicos, objetivos conflitantes e exigências institucionais" (Machado-da-Silva, Fonseca, \& Fernandes, 2000, p. 140). Já o normativo compreende o compartilhamento de um conjunto de normas e rotinas de trabalho pelos membros de uma determinada ocupação, conduzindo a formas comuns de interpretação e de ação em face dos problemas e das exigências organizacionais.

Observa-se que os três mecanismos de isomorfismo institucional, apesar de estarem estreitamente relacionados, derivam de diferentes condições: influência legal (isomorfismo coercitivo), incerteza (mimético) e profissionalização (normativo). Um componente central ligado ao isomorfismo institucional é o conceito de legitimidade. No plano organizacional, implica a aceitação de uma organização no ambiente em que se encontra socialmente imersa (DiMaggio \& Powell, 1983; Meyer \& Rowan, 1977).

Muitas características e ações organizacionais decorrem do isomorfismo. Inicialmente, os interesses de pesquisa acadêmica localizaram-se nas estruturas e práticas organizacionais tratadas no âmbito de cada organização (Meyer \& Rowan, 1977; Tolbert \& Zucker, 1999). Mais recentemente, o foco da análise passou para campos organizacionais e redes interorganizacionais. Conforme afirmam Meyer e Rowan (1977), as demandas das redes de relações locais encorajam o desenvolvimento de estruturas e práticas que coordenam e controlam as atividades organizacionais, contribuindo para a eficiência das organizações.

\section{Estruturas e Práticas}

São muitas as obras científicas que se dedicam ao estudo das práticas sociais. Entre os teóricos que tratam do assunto, certa parte deles advoga que se deve abandonar o dualismo entre estrutura e ação social já há muito tempo presente nas ciências sociais. Assim, este artigo preocupa-se com as práticas de desenvolvimento urbano, partindo do pressuposto de que essas práticas ficam mais bem explicadas sob a perspectiva estruturacionista de Giddens (1978, 2000, 2003), que procura vencer esse dualismo e permite certa flexibilidade epistemológica para o estudo em tela.

A teoria da estruturação fornece uma base consistente para a reconciliação do conceito de agência com o de estrutura. Como ressaltam Machado-da-Silva, Fonseca e Crubelate (2005, p. 25), tornou-se possível, enfim, visualizar a interdependência de estruturas e ações sociais, "sem sucumbir à idéia de causalidade linear entre elas". Nesses termos, Giddens (2003, p. 442) entende estruturas como "traços de memória" que se manifestam, se reproduzem e se reconstroem em qualquer atividade humana 
prática, em que os atores sociais se expressam como tal. "Dessa forma, para além de padrões externos e objetivos construídos para exercer pressão sobre a ação, estruturas são referências que permanecem virtuais e latentes até o momento em que alguma prática social ocorre, tornando-se tanto meio como resultado dela" (Machado-da-Silva et al., 2005, p. 26).

A teoria da estruturação traz em seu cerne essa definição da dualidade da estrutura que, segundo Giddens (2003), se refere à retroatividade da vida social como constituída em práticas sociais. A estrutura é tanto meio como resultado da reprodução das práticas. A estrutura entra simultaneamente na constituição das práticas sociais e existe nos momentos geradores dessa constituição (Cohen, 1999; Giddens, 2000). As estruturas não devem ser conceitualizadas simplesmente como coativas, mas também como habilitadoras (Giddens, 1978).

Em conformidade com essa visão estruturacionista, adotamos a seguinte definição de práticas organizacionais: ações sociais regularizadas e recorrentes que continuamente constroem e reconstroem a organização como um sistema social espaciotemporalmente delimitado. São, portanto, práticas sociais que ocorrem no contexto organizacional.

As práticas sociais caracterizam-se por terem em si durabilidade dinâmica, recursividade e reflexividade. Esses componentes implicam na constatação de que elas, ao tempo que persistem, vão sendo continuamente reconstruídas por atores sociais que as monitoram reflexivamente mediante (re)interpretação de significados no contexto das regras transformacionais. "Aquelas práticas que possuem a maior extensão espaço-temporal ... podem ser designadas como instituições" (Giddens, 2003, p. 20).

Sob a perspectiva de Giddens (2003), investigar os processos de estruturação das práticas sociais é procurar explicar como as estruturas são constituídas pela ação e reciprocamente como a ação é constituída estruturalmente. A estruturação de práticas refere-se abstratamente ao processo dinâmico pelo qual as estruturas passam a existir, envolvendo a interação de significados, normas e poder (Giddens, 1978).

Podemos argumentar que, sob a égide da teoria da estruturação, a análise de redes sociais precisa tratar das dimensões de significação, legitimação e dominação, conforme é possível visualizar na Figura 1. A recursividade entre estrutura e ação, portanto, fundamenta o próprio processo por meio do qual ambas categorias emergem, permeadas por configurações contínuas de interpretação (Machadoda-Silva et al., 2005).

Figura 1: Dualidade da Estrutura em Interação

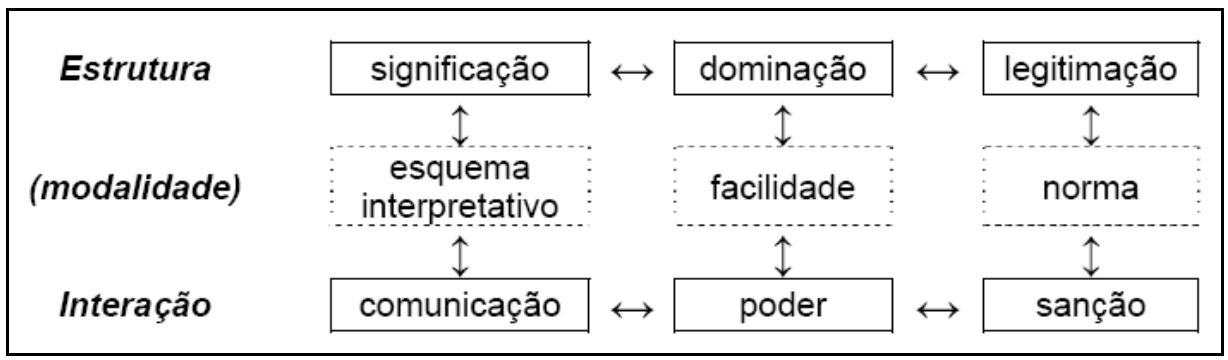

Fonte: Giddens (2003, p. 34).

Assim, a estrutura analítica representada na Figura 1 orientou os procedimentos metodológicos explicitados a seguir e a consequente análise do processo de estruturação da rede interorganizacional dos municípios da RMC. Nessa mesma linha de análise, consideramos as práticas de desenvolvimento urbano adotadas no âmbito da configuração da rede de relacionamentos. 


\section{Procedimentos Metodológicos}

Com o objetivo de visualizar a integração dos conceitos e noções delineados no quadro de referência conceitual, bem como de evidenciar a forma como orientam o presente estudo, apresentamos na Figura 2 o esquema de relacionamento das principais categorias analíticas do estudo.

Figura 2: Integração das Categorias Analíticas

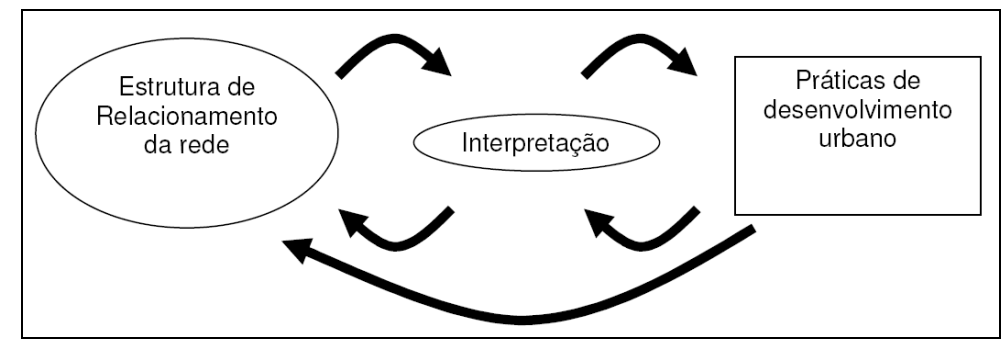

A presente pesquisa caracteriza-se como sendo de perspectiva mista ao se valer de dados quantitativos para análise de uma rede social (J. P. Scott, 2000) e de uma abordagem descritivoqualitativa para a explicação da influência da rede nas práticas de desenvolvimento urbano. O nível de análise do estudo é a rede interorganizacional composta pelos municípios da RMC e a unidade de análise são os atores organizacionais que a integram.

A investigação é de natureza seccional com avaliação longitudinal, vez que acontecimentos passados foram resgatados mediante análise de entrevistas realizadas com 62 gestores públicos e por meio do exame de dados secundários. A média de tempo de serviço dos entrevistados nas funções que exercem na organização (6,3 anos) facilitou o resgate de acontecimentos passados, possibilitando alguma avaliação longitudinal.

O problema de pesquisa orientador deste trabalho requereu a coleta de dados de todos os atores organizacionais de interesse, pois não se trata simplesmente de identificar uma rede, mas de estudar as relações entre organizações definidas, a priori, por meio do critério de co-responsabilidade pelo desenvolvimento urbano na RMC. Assim, todas as 26 prefeituras integrantes da RMC foram consideradas. Além delas, foram incluídos mais 10 órgãos públicos diretamente envolvidos com o planejamento urbanístico da RMC, totalizando as 36 organizações relacionadas na Tabela 1.

A coleta de dados deu-se em três etapas em um período de quatro meses. Os dados secundários foram obtidos de jornais, sites, leis, contratos e arquivos dos municípios e dos outros órgãos integrantes da rede de relacionamentos, bem como de duas outras organizações: Instituto Paranaense de desenvolvimento econômico e social [IPARDES] e Observatório das Metrópoles. Os dados primários foram coletados, primeiramente, mediante questionário aplicado nas 36 organizações em estudo, e, a seguir, por meio de 62 entrevistas semi-estruturadas com prefeitos, secretários municipais e dirigentes do nível estratégico das demais organizações.

Ao levar a efeito a análise inicial da estrutura das relações, verificamos a presença de inconsistências que mereciam ser investigadas com maior profundidade. A partir dessa avaliação, passamos a realizar, sistematicamente, a triangulação dos dados. Tal procedimento possibilitou a validação das relações e evitou o risco de prejudicar conceitos como o de multiplicidade. Além disso, deu margem ao detalhamento mais preciso de dois conteúdos predominantes na rede interorganizacional: um administrativo e outro mais propriamente técnico sobre urbanismo. 


\section{A SituaçÃo em Estudo: o Contexto Metropolitano de Curitiba}

A RMC foi instituída em 1973 no corpo da Lei Federal 14/73 e agrega, atualmente, 26 municípios: 14 deles fazem parte da constituição original, cinco resultaram de desmembramentos da composição original e sete foram integrados aos limites regionais pela legislação estadual (IPARDES, 2006).

Em análise solicitada pelo Governo Federal ao Observatório das Metrópoles, foram verificadas diferenças econômicas e sociais significativas entre municípios da RMC. Os índices de urbanização variam de $100 \%$ (município de Curitiba) a 11,8\% (município Doutor Ulysses). De modo geral, dois conjuntos de municípios fazem parte da RMC: os mais fortemente integrados situam-se em torno do pólo metropolitano e aqueles com níveis menores de integração, que se localizam praticamente à margem dos processos típicos do fenômeno urbano (IPARDES, 2006).

A região tem características bem peculiares, sobretudo por ter como pólo uma cidade reconhecida nacional e internacionalmente em razão de seu planejamento urbano arrojado e eficiente. Essa circunstância torna-se relevante pelo simples fato de Curitiba ter-se transformado em modelo de sucesso de práticas de urbanismo que, todavia, "se tornam inadequadas, quando a problemática urbana assume outra dimensão" (Firkowski, 2002, p. 2), ou seja, a dimensão metropolitana.

Cabe ressaltar que o processo de planejamento urbano de Curitiba tem origem praticamente nos anos 60 do século passado com o Plano Preliminar de Urbanismo, que se tornou Plano Diretor por meio da Lei 2828/66. Em 1965 foi criado o Instituto de Pesquisa e Planejamento Urbano de Curitiba, o IPPUC, com a finalidade de que um grupo de técnicos da Prefeitura Municipal pudesse acompanhar todas as etapas de elaboração do Plano Preliminar de Urbanismo.

Também na década de 60 do século passado, foi criada a Coordenação da Região Metropolitana de Curitiba [COMEC], como entidade autárquica do Governo do Estado do Paraná, com a atribuição de integrar e organizar o planejamento e a execução de funções públicas de interesse comum da população e dos municípios que compõem a RMC. Essas funções corporificam-se no site da COMEC pela importância que ela atribui, no âmbito da RMC, ao planejamento integrado de desenvolvimento econômico e social, ao controle do uso e da ocupação do solo, à habitação, ao abastecimento de água, ao manejo de resíduos sólidos, ao transporte coletivo intermunicipal, e assim por diante. A COMEC vem desenvolvendo planos e programas com o objetivo de consolidar a proposta de integrar a ação do setor público na RMC.

Nesse sentido, a COMEC apresentou, no ano de 1978, o Plano de Desenvolvimento Integrado (PDI/78), que, pela primeira vez, abordou de modo global os problemas dos diferentes municípios da RMC. O PDI/78 passou por duas revisões até a constituição do PDI/RMC, em 2001. Todavia, tanto o PDI/78 quanto a revisão proposta em 2001 não se efetivaram. Como afirma Alcidino Bittencourt Pereira, Diretor-Presidente da COMEC, em discurso de 20 de agosto de 2005, na Conferência Regional das Cidades da Região Metropolitana de Curitiba: "faltou entrosamento com as políticas setoriais do Estado e com as prefeituras municipais para que diretrizes gerais pudessem ser concretizadas" (Pereira, 2005, p. 2). Em vez de primeiro planejar para depois executar obras, esta ordem foi invertida, em detrimento dos interesses comuns da RMC.

Com o advento do Estatuto das Cidades, Lei Federal $n^{\circ}$. 10.257/01, todos os municípios da RMC foram enquadrados em um ou mais incisos do Artigo 41, tendo, portanto, obrigatoriedade na execução do Plano Diretor. Dessa forma, cada município da RMC convive, atualmente, com a expectativa de mudanças a serem levadas a efeito em decorrência do Estatuto das Cidades.

\section{Organizações Responsáveis pelo Planejamento Urbanístico}

A Constituição Federal (1988), sobretudo em seu artigo 182, deixa bem definida as responsabilidades da União, Estados e Municípios na Política de desenvolvimento urbano. Assim, o 
município é responsável pelo planejamento, financiamento, gestão, execução e fiscalização das ações do desenvolvimento urbano, com o apoio e a ação subsidiária dos Estados e da União. Da consulta de documentos e instrumentos legais, verificamos a presença de diversidades na estrutura do Poder Executivo de cada município da RMC, sobretudo no que se refere aos setores com funções específicas de urbanismo. Algumas prefeituras são constituídas por secretarias de urbanismo, outras por secretarias de desenvolvimento urbano, outras dividem as funções inerentes ao urbanismo por mais de uma secretaria ou departamento ou até mesmo gerência, caso do município Fazenda Rio Grande. Diante dessa circunstância, definimos as prefeituras como as organizações responsáveis pelo planejamento urbanístico de cada município.

Além das prefeituras, da COMEC e do IPPUC, o exame das diversas legislações permitiu-nos também incluir oito outros órgãos públicos como responsáveis pelo planejamento urbanístico. Todos eles estão listados na Tabela 1.

Tabela 1: Organizações Responsáveis pelo Planejamento Urbanístico na RMC

\begin{tabular}{|l|l|}
\hline \multirow{2}{*}{ 26 Prefeituras } & $\begin{array}{l}\text { Adrianópolis, Agudos do Sul, Almirante Tamandaré, Araucária, Balsa Nova, } \\
\text { Bocaiúva do Sul, Campina Grande do Sul, Campo Largo, Campo Magro, Cerro } \\
\text { Azul, Colombo, Contenda, Curitiba, Doutor Ulysses, Fazenda Rio Grande, } \\
\text { Itaperuçu, Lapa, Mandirituba, Pinhais, Piraquara, Quatro Barras, Quitandinha, } \\
\text { Rio Branco do Sul, São José dos Pinhais, Tijucas do Sul e Tunas do Paraná. }\end{array}$ \\
\hline \multirow{2}{*}{ Órgãos estaduais } & SEDU - Secretaria de Estado do Desenvolvimento Urbano. \\
\cline { 2 - 2 } & SEMA - Secretaria de Estado do Meio Ambiente. \\
\hline \multirow{2}{*}{\begin{tabular}{l} 
Órgãos vinculados ao do Paraná \\
\cline { 2 - 2 }
\end{tabular}} & COHAPAR - A Companhia de Habitação do Paraná. \\
\cline { 2 - 2 } & SANEPAR - A Companhia de Saneamento do Paraná. \\
\cline { 2 - 2 } & COPEL - A Companhia Paranaense de Energia. \\
\hline \multirow{2}{*}{ Órgão Metropolitano } & COMEC - Coordenação da Região Metropolitana de Curitiba. \\
\hline \multirow{2}{*}{$\begin{array}{l}\text { Órgãos do município } \\
\text { de Curitiba }\end{array}$} & IPPUC - Instituto de Pesquisas e Planejamento Urbano de Curitiba. \\
\cline { 2 - 2 } & SMAM (Curitiba-PR) - Secretaria Municipal para Assuntos Metropolitanos. \\
\cline { 2 - 2 } & URBS - Urbanização de Curitiba S.A. \\
\hline \multirow{2}{*}{ Associação regional } & ASSOMEC - Associação dos Municípios da Região Metropolitana de Curitiba. \\
\hline \multirow{2}{*}{ Fonte: dados secundários da pesquisa }
\end{tabular}

Fonte: dados secundários da pesquisa.

Consta da Tabela 1: a) a Secretaria de Estado do Desenvolvimento Urbano [SEDU], que tem como missão definir as políticas, o planejamento, a execução, a coordenação e o controle das atividades ligadas ao desenvolvimento urbano e regional, além de integrar os municípios, a fim de ordenar o desenvolvimento das cidades e garantir o bem-estar dos habitantes; b) a Associação dos Municípios da Região Metropolitana de Curitiba [ASSOMEC], que objetiva ampliar e fortalecer as capacidades administrativas, econômicas e sociais dos municípios associados e promover o estabelecimento da cooperação entre os municípios e os prefeitos; c) a Secretaria Municipal para Assuntos Metropolitanos [SMAM], órgão do município de Curitiba que busca implementar políticas públicas de desenvolvimento do Município de Curitiba, em conjunto com os demais municípios da RMC; d) a Urbanização de Curitiba S.A. [URBS], uma empresa de economia mista que administra a Rede Integrada de Transportes [RIT], integrando 12 municípios da Região Metropolitana; e) a Secretaria de Estado do Meio Ambiente e Recursos Hídricos [SEMA], com a finalidade de formular e executar as 
políticas de meio ambiente, de recursos hídricos, florestal, cartográfica, agrário-fundiária, de controle da erosão e de saneamento ambiental; f) a Companhia de Habitação do Paraná [COHAPAR], com a finalidade de integrar o Paraná no sistema financeiro da habitação; g) a Companhia de Saneamento do Paraná [SANEPAR], empresa estatal de economia mista, que cuida das ações de saneamento básico em todo o Estado do Paraná; e h) a Companhia Paranaense de Energia [COPEL], com a missão de provimento de energia elétrica que cobre praticamente todo o Estado do Paraná.

\section{Práticas de Desenvolvimento Urbano}

O desenvolvimento, sobretudo em conexão especificamente com o ambiente urbano, é entendido, em convergência com Souza (2005), como mudança social positiva. Em termos bem simples e puramente introdutórios, afirmamos que se está diante de um processo de desenvolvimento social e espacial quando se constata melhoria da qualidade de vida e aumento da justiça social. No caso, a mudança social positiva precisa contemplar não apenas as relações sociais, mas, também, a própria noção de espacialidade.

De acordo com o Estatuto das Cidades, deve-se entender por práticas de desenvolvimento urbano aquelas implementadas no sentido de serem cumpridas as funções sociais da cidade e da propriedade urbana, que assegurem o atendimento das necessidades dos cidadãos em termos de qualidade de vida e da justiça social (Lei n. 10.257, 2001). As principais categorias de definição de práticas constantes do Estatuto das Cidades estão apresentadas na Tabela 2.

Tabela 2: Categorias das Práticas de Desenvolvimento Urbano

\begin{tabular}{|l|l|l|}
\hline \multicolumn{2}{|c|}{ CATEGORIAS } & \\
\hline a. & Ordenação do uso e ocupação do solo & b. Moradia - habitação \\
\hline c. & Segurança & d. Meio ambiente ecologicamente equilibrado \\
\hline e. & $\begin{array}{l}\text { Saneamento - esgotamento sanitário e resíduos } \\
\text { sólidos }\end{array}$ & f. $\quad \begin{array}{l}\text { Mobilidade urbana - sistema viário - } \\
\text { transporte público }\end{array}$ \\
\hline g. & Cultura e patrimônio cultural & h. Lazer e esporte \\
\hline i. & Gestão da organização & \\
\hline
\end{tabular}

Fonte: adaptado do Estatuto das Cidades.

Para a identificação das práticas foi adotado o conceito desenvolvido por Giddens (1978) e adaptado ao campo do desenvolvimento urbano. A análise concentrou-se no que era efetivamente desenvolvido no âmbito de cada organização, visando a resgatar ações continuadas e regulares conectadas com o urbanismo. Nessa linha de raciocínio, a análise de conteúdo das entrevistas semi-estruturadas permitiu identificar as principais práticas adotadas pelos municípios da RMC, com base na definição preliminar de categorias relacionadas na Tabela 2. Identificamos 24 práticas distribuídas entre essas diversas categorias, como se pode visualizar na Tabela 3. 
Tabela 3: Práticas de Desenvolvimento Urbano

\begin{tabular}{|c|c|c|}
\hline CATEGORIAS & PRÁTICAS & FREQÜÊNCIA \\
\hline \multirow[t]{4}{*}{ Ordenação do uso e ocupação do solo } & $\begin{array}{l}\text { Disposição de documentos esclarecedores do uso } \\
\text { do solo aos cidadãos. }\end{array}$ & 6 \\
\hline & Zoneamento & 13 \\
\hline & $\begin{array}{l}\text { Exigência e aprovação de projetos para a } \\
\text { ordenação do uso e ocupação do solo. }\end{array}$ & 23 \\
\hline & $\begin{array}{l}\text { Decretar área de imóvel particular de interesse } \\
\text { público para fins de desapropriação. }\end{array}$ & 5 \\
\hline \multirow[t]{3}{*}{ Moradia - habitação } & $\begin{array}{l}\text { Doação de terrenos para a construção de casas } \\
\text { populares }\end{array}$ & 12 \\
\hline & $\begin{array}{l}\text { Definição de zonas destinadas à habitação de } \\
\text { interesse social (ZEIS). }\end{array}$ & 4 \\
\hline & $\begin{array}{l}\text { Concessão de isenção de taxas e impostos } \\
\text { municipais para moradores de baixo poder } \\
\text { aquisitivo. }\end{array}$ & 7 \\
\hline Segurança & $\begin{array}{l}\text { Instituição de guardas municipais para proteção de } \\
\text { bens, serviços e instituições. }\end{array}$ & 12 \\
\hline \multirow[t]{3}{*}{$\begin{array}{l}\text { Meio ambiente ecologicamente } \\
\text { equilibrado }\end{array}$} & $\begin{array}{l}\text { Recuperação ambiental de um curso d'água } \\
\text { urbano. }\end{array}$ & 5 \\
\hline & Regularização fundiária & 9 \\
\hline & $\begin{array}{l}\text { Criação e manutenção de parques de interesse } \\
\text { urbanístico ou ambiental. }\end{array}$ & 5 \\
\hline \multirow[t]{2}{*}{$\begin{array}{l}\text { Saneamento - esgotamento sanitário } \\
\text { resíduos sólidos }\end{array}$} & $\begin{array}{l}\text { Utilização de aterros sanitários em consórcio com } \\
\text { outros municípios. }\end{array}$ & 15 \\
\hline & Terceirização da coleta de lixo. & 4 \\
\hline \multirow{2}{*}{$\begin{array}{l}\text { Mobilidade urbana - sistema viário - } \\
\text { transporte público }\end{array}$} & Manutenção de estradas e rodovias & 12 \\
\hline & Integração de transporte coletivo & 12 \\
\hline \multirow[t]{3}{*}{ Cultura e Patrimônio Cultural } & Proteção do patrimônio histórico-cultural. & 8 \\
\hline & $\begin{array}{l}\text { Implantação e manutenção de equipamentos } \\
\text { públicos próprios para atividades culturais. }\end{array}$ & 8 \\
\hline & Nominação de ruas no Perímetro Urbano & 3 \\
\hline Lazer e esporte & $\begin{array}{l}\text { Implantação de equipamentos públicos para lazer e } \\
\text { esporte. }\end{array}$ & 21 \\
\hline \multirow[t]{5}{*}{ Gestão da organização } & Elaboração e atualização do Plano Diretor & 26 \\
\hline & $\begin{array}{l}\text { Busca de apoio financeiro de níveis } \\
\text { governamentais superiores para a realização de } \\
\text { projetos. }\end{array}$ & 21 \\
\hline & $\begin{array}{l}\text { Consulta a Internet para busca de soluções } \\
\text { urbanísticas de sucesso. }\end{array}$ & 12 \\
\hline & $\begin{array}{l}\text { Apoio da COHAPAR para a gestão da construção } \\
\text { de unidades habitacionais. }\end{array}$ & 7 \\
\hline & $\begin{array}{l}\text { Criação e manutenção de órgão integrador das } \\
\text { ações de outros órgãos responsáveis pela } \\
\text { organização urbanística do município. }\end{array}$ & 2 \\
\hline
\end{tabular}

As praticas organizacionais alinhavadas na Tabela 3 são auto-explicativas. Outras práticas nas diversas categorias foram identificadas por meio da análise dos dados secundários. No entanto, selecionamos aquelas reputadas pelos gestores públicos como sendo as mais importantes. Nas seções que se seguem, vamos abordar aquelas mais influenciadas pela estrutura de relações das organizações estudadas. 


\section{A Estrutura de Relações e as Práticas Urbanísticas}

As redes sociais são caracterizadas pelo conteúdo das relações que a constituem, podendo variar de contexto para contexto (Aldrich, 1979). Na presente investigação, contudo, as relações de maior interesse são de ordem instrumental, ou seja, são aqueles laços preenchidos pelas práticas cotidianas, visando objetivos concretos específicos para o desenvolvimento urbano. Após o tratamento dos dados, o conteúdo relacional é apresentado na Tabela 4.

Tabela 4: Conteúdo Relacional

\begin{tabular}{lcc}
\hline Conteúdo relacional & Respostas & Porcentagem $(\%)$ \\
\hline Pressão política & 8 & 1,32 \\
Troca de informações técnicas & 262 & 43,02 \\
Troca de informações administrativas & 316 & 52,05 \\
Redução de custos & 7 & 1,15 \\
Atividades sociais & 15 & 2,46 \\
\hline Total das relações & 608 & 100 \\
\hline Fonte: dados primários da pesquisa &
\end{tabular}

A Tabela 4 revela a preponderância das relações de conteúdo técnico e de relações administrativas. Aquelas afetam diretamente as questões urbanísticas enquanto as relações administrativas têm a ver com as atividades meio para fins de urbanismo. Tendo em vista esse resultado, decidimos analisar, além da rede que integra todos os conteúdos, duas outras separadamente: a de conteúdo técnico e a de conteúdo administrativo.

As matrizes, posteriormente analisadas com auxílio do programa UCINET, foram elaboradas permitindo o cálculo das centralidades, expostas na Tabela 5. As medidas são assim interpretadas: quando o laço de um ator em estudo sai no sentido de outro, essa medida apresenta-se em termos de OutDegre; o inverso é expresso pelo InDegree.

Tabela 5: Centralidade Administrativa e Técnica

\begin{tabular}{l|rrrr}
\hline Centralidade & \multicolumn{3}{c}{ ADMINISTRATIVA } & \multicolumn{2}{c}{ TÉCNICA } \\
\hline & OutDegree & InDegree & OutDegree & InDegree \\
COMEC & 1,000 & 3,000 & 17,000 & 28,000 \\
SEDU & 30,000 & 31,000 & 32,000 & 27,000 \\
ASSOMEC & 30,000 & 16,000 & 1,000 & 4,000 \\
IPPUC & 2,000 & 2,000 & 6,000 & 9,000 \\
URBS & 15,000 & 5,000 & 5,000 & 17,000 \\
SMAN & 2,000 & 6,000 & 10,000 & 9,000 \\
COHAPAR & 29,000 & 28,000 & 31,000 & 13,000 \\
SANEPAR & 22,000 & 23,000 & 4,000 & 25,000 \\
SEMA & 1,000 & 7,000 & 13,000 & 14,000 \\
COPEL & 26,000 & 26,000 & 2,000 & 2,000 \\
Adrianópolis & 4,000 & 5,000 & 3,000 & 2,000 \\
Agudos do Sul & 4,000 & 4,000 & 4,000 & 2,000 \\
Alte Tamandaré & 10,000 & 7,000 & 11,000 & 8,000 \\
Araucária & 6,000 & 8,000 & 5,000 & 4,000 \\
Balsa Nova & 8,000 & 6,000 & 4,000 & 2,000 \\
Bocaiúva do Sul & 6,000 & 7,000 & 6,000 & 3,000 \\
Camp. Gde do Sul & 9,000 & 9,000 & 7,000 & 7,000 \\
Campo Largo & 10,000 & 7,000 & 7,000 & 4,000 \\
Campo Magro & 5,000 & 8,000 & 9,000 & 4,000 \\
Cerro Azul & 4,000 & 6,000 & 2,000 & 4,000 \\
\hline
\end{tabular}


Tabela 5 (continuação): Centralidade Administrativa e Técnica

\begin{tabular}{l|rrrr}
\hline Centralidades & \multicolumn{3}{c}{ ADMINISTRATIVA } & \multicolumn{2}{c}{ TÉCNICA } \\
\hline Colombo & 4,000 & 9,000 & 6,000 & 8,000 \\
Contenda & 4,000 & 8,000 & 3,000 & 4,000 \\
Curitiba & 12,000 & 14,000 & 10,000 & 12,000 \\
Dr Ulysses & 5,000 & 4,000 & 2,000 & 2,000 \\
Faz Rio Grande & 8,000 & 8,000 & 10,000 & 7,000 \\
Itaperuçu & 5,000 & 7,000 & 3,000 & 4,000 \\
Lapa & 7,000 & 5,000 & 3,000 & 2,000 \\
Mandirituba & 5,000 & 5,000 & 3,000 & 3,000 \\
Pinhais & 10,000 & 7,000 & 10,000 & 5,000 \\
Piraquara & 7,000 & 7,000 & 4,000 & 4,000 \\
Quatro Barras & 6,000 & 6,000 & 5,000 & 5,000 \\
Quitandinha & 5,000 & 5,000 & 2,000 & 2,000 \\
Rio Branco do Sul & 4,000 & 6,000 & 4,000 & 3,000 \\
São J. dos Pinhais & 8,000 & 9,000 & 11,000 & 8,000 \\
Tijucas do Sul & 5,000 & 5,000 & 4,000 & 3,000 \\
Tunas do Paraná & 4,000 & 4,000 & 3,000 & 2,000 \\
\hline Fon
\end{tabular}

Fonte: dados primários da pesquisa.

\section{Estrutura das Relações entre os Municípios}

A rede de relacionamentos entre os municípios da RMC exprime as relações diretas entre as prefeituras. O nó de cor azul representa a prefeitura da cidade pólo da RMC, Curitiba, enquanto os nós vermelhos referem-se às outras vinte e cinco prefeituras. É possível perceber as centralidades de grau (degree) pelos tamanhos dos nós e pelas suas posições fisicamente centrais no gráfico.

Figura 3: Rede de Relações entre os Municípios da RMC

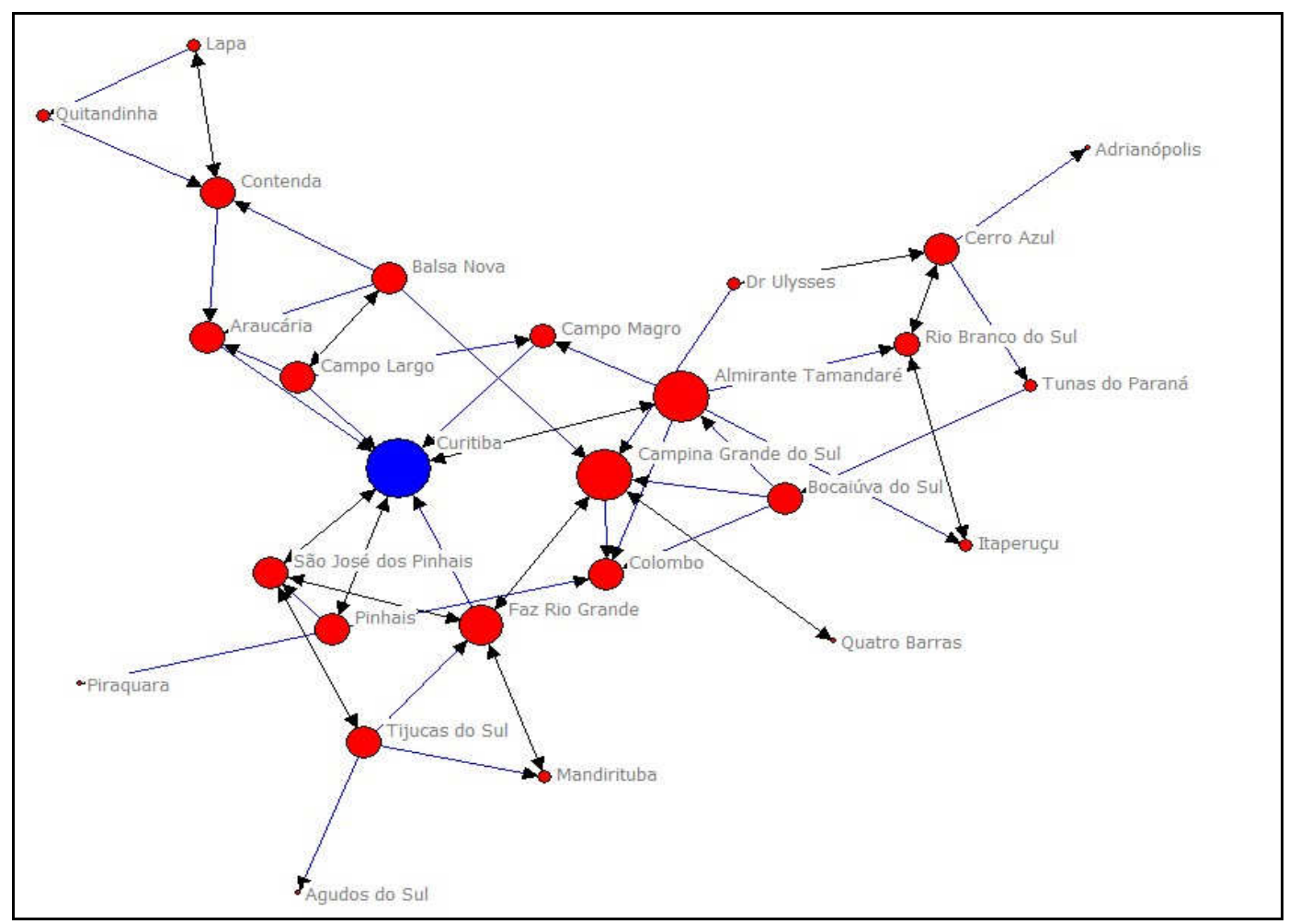

Fonte: dados primários da pesquisa. 
A estrutura de relações representada na Figura 3 demonstra pequena densidade (Dens $=0.08262$ ), comparada à densidade da rede da Figura 4 (Dens $=0.3452)$ com a participação das outras organizações governamentais, permitindo concluir, em conformidade com Borgatti, Everett e Freeman (2002), a existência de baixo grau de coesão e homogeneidade entre os municípios. Essa circunstância torna evidente o insuficiente relacionamento para fins urbanísticos entre os municípios da RMC. Além disso, verifica-se que as relações acontecem, em sua maioria, entre os municípios no entorno de Curitiba, cidade pólo da RMC.

Figura 4: Rede de Relações entre as Organizações da RMC

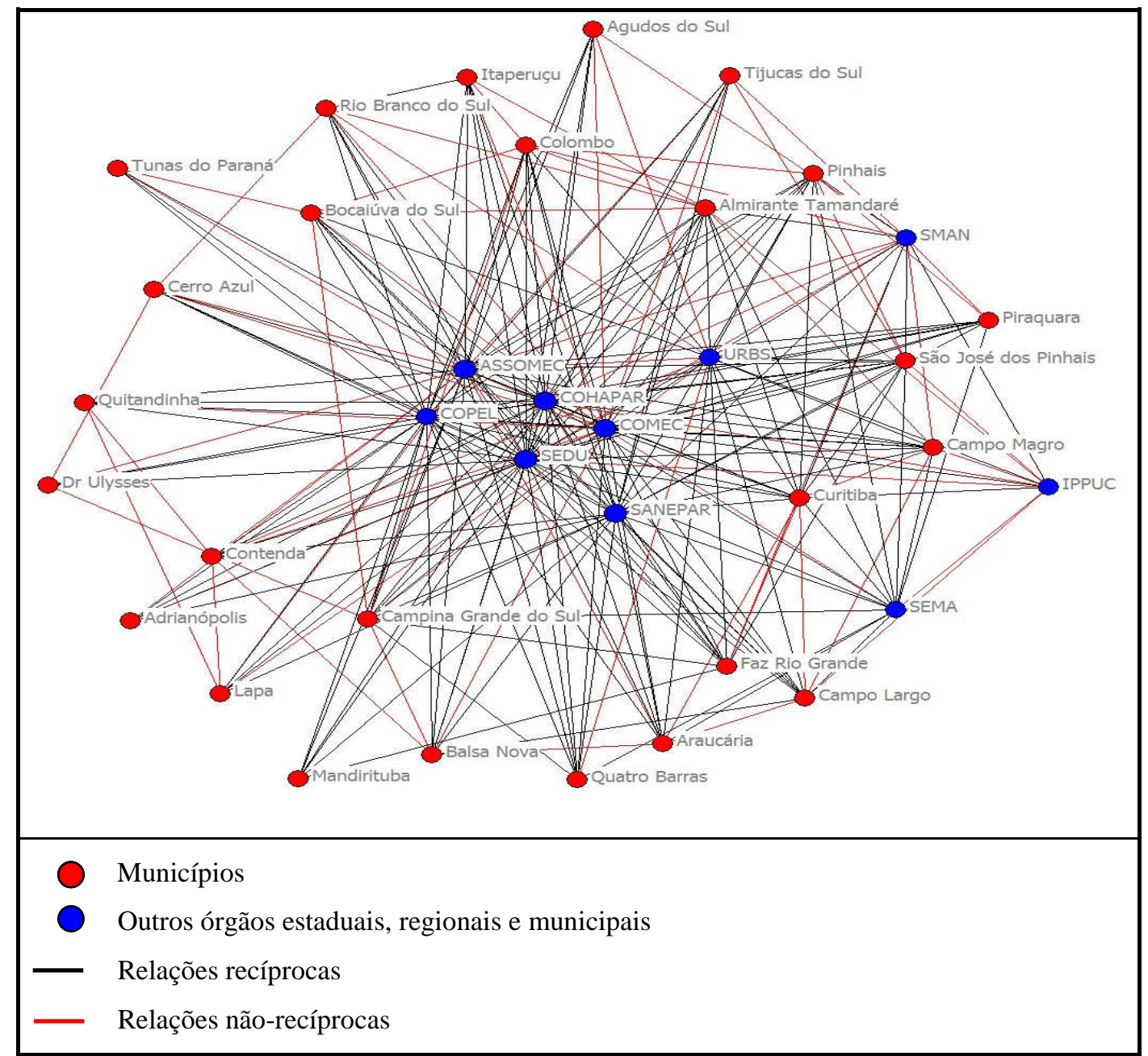

Fonte: dados primários da pesquisa.

A configuração espacial demonstra a distribuição das organizações com maior grau de relações no centro e a localização daquelas menos relacionadas na periferia. Trata-se da representação de uma matriz não-simétrica, expressando com linhas pretas as relações recíprocas e com linhas vermelhas as não-recíprocas. A reciprocidade caracteriza-se por relações de cooperação e colaboração, em razão da intencionalidade e de objetivos mútuos. Já a assimetria refere-se mais fortemente às relações de poder e controle. Assim, a rede representada na Figura 4 contém ambos os tipos de relações.

O padrão de relacionamento na rede é pouco disperso e configura-se relativamente agrupado em torno de um núcleo. Algumas organizações mostram-se mais centrais em relação a outras que estão localizadas em regiões mais periféricas da rede. É possível visualizar, portanto, a ocorrência de heterogeneidade entre as organizações envolvidas no planejamento urbanístico da RMC. Algumas delas apresentam mais de trinta laços, enquanto outras não mais de três, estando, pois, praticamente alienadas na rede de relacionamentos. 


\section{Influências nas Práticas de Desenvolvimento Urbano}

A Coordenação da Região Metropolitana [COMEC] destaca-se na rede de conteúdo técnico e sua intensa centralidade (InDegree $=28$ ) influencia diretamente as práticas de exigência e aprovação de projetos para a ordenação do uso e ocupação do solo. Essa exigência tem como base a Lei Federal $\mathrm{n}^{\circ}$. 6.766, de 19 de dezembro de 1979, que dispõe sobre o parcelamento do solo urbano. Ela define requisitos urbanísticos e determina que, para o caso da RMC, o exame e a anuência prévia à aprovação do projeto caberão à COMEC.

Tal exigência constitui um obstáculo a atrapalhar a administração do município, na visão de algumas prefeituras visitadas. Outras consideram que é uma maneira de justificar a não autorização para o eleitor, uma vez que há a dependência de aprovação de órgão superior. Independentemente da necessidade ou não dessa prática, 18 municípios referiram-se a ela como ação adotada regularmente. Representantes de outros municípios, incluindo Curitiba, que é o município pólo, afirmaram que não cumprem esta formalidade pelo simples fato de que só atrapalha, conforme demonstram a seguir os fragmentos (1) e (2) de entrevistas com um Secretário de urbanismo e um Secretário de obras.

(1) "a COMEC tem gente muito boa e competente, mas não tem estrutura para analisar as dezenas de solicitações que chegam por força da lei. Aqui em [nome de município da RMC] faz muito tempo que não se manda um projeto para lá”.

(2) "nós mandamos um projeto há mais de um ano, mas até agora nada retornou".

São fragmentos que, apesar da centralidade na rede, sinalizam certo esvaziamento experimentado pela COMEC e a fragilidade em que o órgão metropolitano se encontra no que concerne à capacidade de trabalho. Evidencia-se, ainda, a presença efetiva da dimensão coercitiva nessa prática, pois os municípios simplesmente obedecem à lei sob pena de não terem suas ordenações do solo legalizadas. A lógica de que a legalização do procedimento urbanístico diante da COMEC gera a legitimidade necessária revela, também, a valorização da norma. A aprovação funciona como uma espécie de certificação de credibilidade, diante de órgão governamentais superiores. Tal certificação permite acesso aos benefícios de financiamento e de apoio técnico nos empreendimentos relativos ao projeto aprovado.

A estrutura de relacionamento demonstra e as entrevistas comprovaram que essa é a prática em que a COMEC é mais citada. Dos vinte e três municípios que mantêm relações com a organização, apenas dois citaram outras atividades daquele órgão coordenador, responsável por várias atividades de integração que não acontecem. Dos três municípios que com ela não se relacionam para a legalização dos projetos de uso do solo, dois deles fizeram menção a ela apenas para dizer que não vêem razão para aquela burocracia.

Outra prática destacada pelos dirigentes é a concessão de isenção de taxas e impostos municipais para moradores de baixo poder aquisitivo. Apesar de apenas sete organizações terem feito referência a esta prática, ela sobressaiu por ser eminentemente administrativa e influenciar sobremaneira os destinos técnicos urbanísticos das cidades. Na análise da rede, percebe-se um nível de centralidade baixo entre as prefeituras que levantaram a questão. Tal ocorrência permitiu compreender que o fraco relacionamento entre essas organizações conduzem a uma menor fruição das informações que circulam na rede. Assim, elas ficam socialmente isoladas no contexto da RMC, o que lhes proporciona poucas oportunidades de troca de experiências e entendimento com outros municípios, que já desenvolvem padrões administrativos refinados na gestão de impostos.

Nessa direção, fica evidente outra influência da estrutura de relações no que concerne à isenção de impostos. Trata-se das relações com a SEDU e a COHAPAR, que possuem alto nível de centralidade na rede administrativa. Essas relações implicam na solução dos problemas de carência financeira do município por via transversa, colaborando, pois, com a inércia administrativa que se contrapõe até mesmo às determinações legais em que se baseiam os impostos. 
Essa prática evidencia a presença de certas características culturais brasileiras nessas organizações públicas. Esses traços estão relacionados à nossa origem patrimonialista e foram ressaltados diversas vezes pelos entrevistados: o jeitinho brasileiro, benefícios paternalistas de governantes e formalismo (Machado-da-Silva, Guarido Filho, Nascimento, \& Oliveira, 2003). São práticas que vêm demonstrar que as organizações se configuram como sistemas sócio-culturais (W. R. Scott, 2008). Como ressaltam Barley e Tolbert (1997), as influências culturais na tomada de decisão e nas estruturas formais tendem a ser ressaltadas pelo uso da perspectiva institucional de análise.

A multiplicidade das relações entre as organizações fica evidente nas práticas concernentes à elaboração do Plano Diretor ${ }^{(2)}$, que tem sido palco de discussões municipais, sobretudo após a instituição do Estatuto das Cidades (Lei n. 10.257, 2001). São práticas presentes nos 26 municípios da RMC, em diferentes estágios de desenvolvimento, e implicam em ações que envolvem procedimentos técnicos e administrativos, bem como relações interorganizacionas de natureza variadas. Apresentamse eminentemente técnicas no momento em que são discutidas as estratégias a serem adotadas no Plano Diretor e transmudam para administrativas quando os municípios buscam financiamentos para custear as várias atividades necessárias à sua elaboração.

No centro das discussões do Plano Diretor está a SEDU. Após a determinação da Lei Estadual nº. 15.229 de 25 de julho de 2006, em que o Governo do Estado do Paraná "somente firmará convênios de financiamento de obras de infra-estrutura e serviços com municípios que disponham de Planos Diretores que observem o Estatuto das Cidades", a SEDU iniciou uma fase de programas com a finalidade de oferecer apoio técnico e financeiro para esse fim. As relações advindas dessa prática foram as mais evidenciadas durante as entrevistas. Isso explica grande parte da densidade apresentada na análise da rede e demonstra essa prática influenciando a estrutura de relações.

No curso da investigação, constatamos a carência de equipes de técnicos especializados e com tempo dedicado exclusivamente a essa atividade nos municípios. Tal circunstância, mencionada em diversos documentos e nos depoimentos de vários gestores, ensejou a terceirização da elaboração do plano para empresas de arquitetura e engenharia. Dos 26 municípios consultados, 21 (80,7\%) declararam a utilização de uma empresa especializada, seja para elaboração ou para revalidação dos planos já existentes. Esse fato, adicionado à normalização sugerida pelo Estatuto das Cidades, conduziu a uma evidente semelhança entre os diversos planos nas suas formas e estratégias, no que se refere a habitação, meio ambiente, patrimônio cultural, mobilidade urbana, zoneamento, e assim por diante.

Ainda sob a perspectiva de multiplicidade de relações, destacam-se as práticas sob a responsabilidade do IPPUC e do Instituto de Desenvolvimento Urbano [IDU] de São José dos Pinhais. A criação do IPPUC em Curitiba, no ano de 1965, implicou na existência de um órgão responsável por todas as ações relacionadas ao planejamento urbano e ao monitoramento da execução do Plano Diretor da cidade. Mais recentemente, o surgimento do IDU no município vizinho de São José dos Pinhais sugere a recorrência, em outra prefeitura, das práticas relativas a uma organização integradora dos outros órgãos responsáveis pela organização urbanística do município. Dessa forma, nas redes analisadas destaca-se a tríade formada por Curitiba, São José dos Pinhais e IPPUC, que permitiu visualizar canais por meio dos quais fluem informações explicativas da ocorrência de isomorfismo mimético, configurado na adoção do IDU por São José dos Pinhais, com os mesmos procedimentos e arranjos estruturais implementados em Curitiba desde meados dos anos 60 do século passado.

A propósito do IPPUC, a análise das relações demonstra nível incipiente nas ligações diretas com os municípios da RMC. Apesar de ser notório o conhecimento em problemas urbanísticos acumulado por esse Instituto, nas palavras de Firkowski (2002), provavelmente as demandas de Curitiba tenham sido elevadas e mais relevantes que as metropolitanas, que não mereceram atenção maior por parte do IPPUC. Mas o inverso é também verdadeiro, pois o atual presidente do Instituto e o anterior afirmaram em entrevista que o IPPUC é procurado por vários países todos os anos e exporta conhecimento por meio dessas visitas e mediante palestras direcionadas a outras cidades. 


\section{CONSIDERAÇÕES FINAIS}

O presente estudo demonstrou que o relacionamento para fins urbanísticos entre os municípios da RMC está muito aquém das necessidades apontadas pelos próprios dirigentes dessas organizações, o que explica o incipiente fluxo de informações diretas entre as prefeituras. As relações tornam-se mais densas somente com a presença de organizações focais vinculadas diretamente ao Governo do Estado do Paraná. O número de conexões e a influência desses órgãos sobre as práticas organizacionais corroboram empiricamente as idéias de centralidade defendidas por Galaskiewicz (1979), Knoke e Burt (1983) e J. P. Scott (2000).

Desse modo, as práticas relacionadas à elaboração e atualização do Plano Diretor em cada município mostraram-se sobremaneira influenciadas pela centralidade de alguns órgãos estaduais na estrutura da rede. A promulgação da Lei Estadual $\mathrm{n}^{\circ}$. 15.229, além do próprio Estatuto das Cidades, conferiram certo poder regulador aos órgãos estaduais. Eles agem mediante uso de mecanismos coercitivos, aplicando sanções aos municípios que não concluírem o Plano Diretor.

Além disso, observamos a ainda forte presença de nossa herança patrimonialista e a lógica do formalismo orientando o processo de persistência e mudança de formas de fazer e de agir. Vale ressaltar que a grande presença da dimensão regulativa, aliada às características culturais do formalismo, evidenciam um processo de institucionalização de cima para baixo no âmbito da administração pública da RMC.

Tal constatação vem corroborar a afirmação de Machado-da-Silva et al. (2003) no sentido de que esse espaço para a regulação e a coerção decorre das estruturas de poder e do sistema de representação política, de um lado, e da precariedade do conceito de cidadania e da baixa capacidade empreendedora de parcela dos nossos dirigentes e da nossa população, de outro. É nesse contexto que o formalismo dos órgãos estaduais garante espaço e se impõe sobre os municípios que integram a rede da RMC. Nessa direção, observamos a ocorrência de um processo de institucionalização invertido: ao contrário de as práticas de interesse dos cidadãos serem iniciadas e compartilhadas nos municípios, elas são impostas de maneira reguladora dos órgãos estaduais para as prefeituras da RMC.

Verificamos no presente estudo grande semelhança entre os planos diretores dos diversos municípios em razão da padronização decorrente do Estatuto das Cidades, bem como da interferência de profissionais de empresas especializadas e terceirizadas pelas prefeituras. Assim, a presença do isomorfismo normativo encontra-se vinculada ao isomorfismo coercitivo, emprestando-lhe, até certo ponto, um caráter regulador.

$\mathrm{Na}$ análise dos índices de centralidade, fica evidente o posicionamento periférico de alguns municípios na configuração estrutural em exame, demonstrando que a precariedade das relações pode estar dando espaço para a ocorrência de uma estrutura habilitadora de determinadas práticas, como é o caso da concessão de isenção de taxas e impostos em sete municípios. A legalização da ordenação do uso e ocupação do solo junto à COMEC na busca de legitimidade para o acesso a recursos mostram a presença do isomorfismo normativo, possibilitando o compartilhamento dessas normas e de rotinas de trabalho nas práticas das diversas prefeituras da RMC.

Já a presença do isomorfismo mimético corporificou-se na criação do IDU, em São José dos Pinhais, à semelhança do IPPUC, em Curitiba, com a finalidade de reduzir a incerteza ocasionada pelas exigências institucionais da acelerada urbanização. A reprodução da forma organizacional do IPPUC no IDU implica a adoção de procedimentos e arranjos estruturais implementados em Curitiba há mais de quarenta anos.

Constatação importante revelada ao longo do trabalho refere-se à COMEC. Apesar da centralidade dessa organização na rede de relacionamentos, sua influência dá-se tão somente no que concerne a uma única prática dos municípios, qual seja a aprovação de projetos para a ordenação do uso e ocupação do solo. Isto significa que sua atuação situa-se bem aquém da missão de funcionar como 
órgão de coordenação metropolitana. Nesse sentido, $39 \%$ dos entrevistados afirmaram que a COMEC já foi um órgão mais ativo nos assuntos metropolitanos, cerca de 12 anos atrás. Essa situação, aliada à sugestão por dirigentes da própria organização de um novo arranjo institucional presente no novo PDI/2007, revela nitidamente um processo de esvaziamento da COMEC.

À guisa de conclusão, vale reforçar que o crescimento e a complexidade das aglomerações urbanas metropolitanas tornam cada vez mais relevantes determinados processos que possibilitem a sua integração em um competente sistema de gestão para permitir a provisão de serviços públicos e a promoção do desenvolvimento. A RMC ressente-se de uma administração mais eficaz e mais eficiente que consiga ultrapassar as barreiras institucionais da autonomia dos poderes federativos nos três níveis. Esta necessidade ganha cada vez mais importância e exige estudos aprofundados para a definição de modelos mais adequados para o aperfeiçoamento de prefeituras e outros órgãos públicos que atuam no âmbito da RMC.

Artigo recebido em 17.11.2008. Aprovado em 20.05.2009.

\section{NOTAS}

\footnotetext{
${ }^{1}$ Apesar de tratarem de muitas questões comuns, os termos urbanismo e planejamento urbano diferenciam-se sob alguns aspectos importantes. Ambos são entendidos como o estudo do fenômeno urbano em sua dimensão espacial, mas diferem notadamente no tocante às formas de atuação no espaço urbano. Desta maneira, o urbanismo trabalha preocupado inicialmente com uma melhor construção do espaço físico, segundo Souza (2005, p. 112), "uma simples expansão do tecido urbano e sua complexidade". Já o planejamento urbano, antes de agir diretamente no ordenamento físico das cidades, trabalha com os processos que conduzem a um "desenvolvimento socioespacial na cidade e da cidade" (Souza, 2005, p. 112); é a ação do Estado sobre a organização do espaço intra-urbano (Vilaça, F. (2004). Uma contribuição para a história do planejamento urbano no Brasil. In C. Deák \& S. R. Shiffer (Orgs.). O processo de urbanização no Brasil (pp. 169-243). São Paulo: Editora da USP.). De acordo com Ascher, F. (1995). Métapolis ou l'avenir des villes. Paris: Éditions Odile Jacob, o urbanismo deve ser visto de forma ampla como o conjunto das teorias e práticas de aménagement.

${ }^{2}$ Para Villaça (2004), trata-se de um plano que parte de um diagnóstico científico da realidade física, social, econômica, política e administrativa da cidade, do município e de sua região; apresenta um conjunto de propostas para o futuro desenvolvimento socioeconômico e futura organização espacial dos usos do solo urbano, das redes de infra-estrutura e de elementos fundamentais da estrutura urbana, propostas estas definidas para curto, médio e longo prazo, e aprovadas por lei municipal.
}

\section{REFERÊNCIAS BIBLIOGRÁFICAS}

Aldrich, H. (1979). Organizations \& environments. Englewood Cliffs: Prentice-Hall.

Barley, S. R., \& Tolbert, P. S. (1997). Institutionalization and structuration: studying the links between action and institution. Organization Studies, 18(1), 93-117.

Borgatti, S. P., Everett, M. G., \& Freeman, L. C. (2002). UCINET for Windows: software for social network analysis. Harvard: Analytic Tchnologies.

Burt, R. (1983). Applied network analysis: a methodological introduction. California: Sage Publications Inc.

Cohen, I. (1999). Teoria da estruturação e práxis social. In A. Giddens \& J. Turner (Orgs.). Teoria social hoje. São Paulo: UNESP.

Constituição da República Federativa do Brasil de 1988. (1988). Brasília. Recuperado em 10 abril, 2008, de http://www.planalto.gov.br/CCIVIL_03/Constituicao/Constitui\%C3\%A7ao.htm 
Cook, K. S., \& Whitmeyer, J. M. (1992). Two approaches to social structure; exchange theory and network analysis. Annual Review Sociological, 18, 109-127.

DiMaggio, P. J., \& Powell, W. W. (1983). The iron cage revisited: institutioinal isomorphism and collective rationality in organizational field. American Sociological Review, 48(2), 147-160.

Firkowski, O. L. C. F. de (2002, April). Os desafios da gestão metropolitana em Curitiba Globalização e Novos Desafios. Proceedings of the Sixth Conference of the Brazilian Studies Association, Atlanta, Georgia, 6.

Galaskiewicz, J. (1979). The structure of community organizational networks. Social Forces, 57(4), 1346-1364.

Giddens, A. (1978). Novas regras do método sociológico. Rio de Janeiro: Zahar editores.

Giddens, A. (2000). O sentido da modernidade: conversas com Antony Giddens. São Paulo: Fundação Getúlio Vargas.

Giddens, A. (2003). A constituição da sociedade. São Paulo: Martins Fontes.

Granovetter, M. (1976). Network samplin: some first steps. American Journal of Sociology, 81(6), 1287-1303.

Instituto Paranaense de Desenvolvimento Econômico e Social. (2006). Como anda a Metrópole Região Metropolitana de Curitiba. (Equipe de pesquisadores do IPARDES). Ipardes/Observatório das Metrópoles, 190p. Recuperado em 15 abril, 2009, de http://www.ipardes.gov.br/pdf/como_andam_as_metropoles_2006.pdf

Knoke, D., \& Burt, R. (1983). Prominence. In R. Burt \& M. Minor (Eds.). Applied network analysis: a methodological introduction (pp. 196-222). California: Sage Publications.

Knoke, D., \& Laumann, E. (1982). The social organization of national policy domains: an exploration of some structural hypothesis. In P. Marsden \& N. Lin (Eds.). Social structure and network analysis (pp. 255-270). California: Sage Publications.

Lei Estadual n. 15.229, de 25 de julho de 2006. (2006). Dispõe sobre normas para execução do sistema das diretrizes e bases do planejamento e desenvolvimento estadual, nos termos do art. 141, da Constituição Estadual. Curitiba, PR: Diário Oficial do Estado do Paraná.

Lei Federal n. 6.766, de 19 de dezembro de 1979. (1979). Dispõe sobre o parcelamento do solo urbano. Seção 1. Brasília: Diário Oficial da República Federativa do Brasil.

Lei Federal n. 10.257, de 10 de julho de 2001. (2001). Regulamenta os arts. 182 e 183 da Constituição Federal, estabelece diretrizes gerais da política urbana e dá outras providências. Seção 1. Brasília: Diário Oficial da República Federativa do Brasil.

Machado-da-Silva, C. L., Fonseca, V. S., \& Crubellate, J. M. (2005). Unlocking the institutionalization process: insights for an institutionalizing approach. Brazilian Administration Review, 2(1), 1-20.

Machado-da-Silva, C. L., Fonseca, V. S., \& Fernandes, B. H. (2000). Cognição e institucionalização na dinâmica da mudança em organizações. In M. P. Cunha \& S. B. Rodrigues (Orgs.). Estudos organizacionais: novas perspectivas na administração de empresas: uma coletânea lusobrasileira (pp. 123-150). São Paulo: Iglu.

Machado-da-Silva, C. L., Guarido Filho, E. R., Nascimento, M. R., \& Oliveira, P. T. (2003). Institucionalização da mudança na sociedade brasileira: o papel do formalismo. In M. M. F. 
Vieira \& C. A. Carvalho (Orgs.). Organizações, instituições e poder no Brasil (Vol. 1, pp. 179202). Rio de Janeiro: Editora FGV.

Meyer, J. W., \& Rowan, B. (1977). Institutionalized organizations: formal structure as myth and ceremony. America Journal of Sociology, 83(2), 340-362.

Mitchell, J. C. (1976). The concept and use of social networks. In W. M. Evan (Ed.). Interorganizational relations. Pensilvania: University of Pensilvania Press.

Mizruchi, M. S., \& Galaskiewicz, J. (Eds.). (1994). Advances in social networks analysis: research in social and behavioral sciences. London: Sage.

Moreno, J. (1978). Who shall survive? New York: Beacon House Press. (Obra original publicada em 1934).

Oliver, C. (1990). Determinants of interorganizational relationships: integration and future directions. Academy of Management Review, 15(2), 241-265.

Pereira, A. B. (2005, agosto). Política metropolitana. Anais da Conferência das Cidades: Região Metropolitana de Curitiba, Curitiba, PR, Brasil, 20.

Scott, J. P. (2000). Social network analysis: a handbook (2a ed.). London: Sage Publications.

Scott, W. R. (2008). Institutions and organizations (3a ed.). Thousand Oaks, California: Sage Publications.

Souza, M. L. (2005). ABC do desenvolvimento urbano (2a ed.). Rio de Janeiro: Bertrand.

Tolbert, P. S., \& Zucker, L. G. (1999). A institucionalização da teoria institucional. In S. Clegg, C. Hardy, \& W. R. Nord (Orgs.). Handbook de estudos organizacionais (Vol. 1, pp. 196-219). São Paulo: Atlas.

Uehara, E. (1990). Dual exchange theory, social networks, and informal social support. American Journal of Sociology, 96(3), 521-588.

Wasserman, S., \& Faust, K. (1994). Social network analysis: methods and applications. Cambridge: Cambridge University Press.

Wellman, B. (1988). Structural Analysis: from method and metaphor to theory and substance. In B. Wellman \& S. D. Berkowitz (Eds.). Social structures: a network approach (pp. 210-30). Cambridge: Cambridge University Press. 